\title{
Leader
}

\section{Pathology of silicone leakage from breast implants}

\author{
Paul J van Diest, Werner H Beekman, Joris J Hage
}

Silicone breast prostheses have been widely used for several decades. Until recently, about 150000 women received these implants annually in the United States- $80 \%$ for breast augmentation and the others almost exclusively for reconstruction after cancer surgery. ${ }^{1}$ There is little doubt about the beneficial psychological effects of breast implants, but there is increasing awareness of alleged adverse effects of implants containing silicone. These mainly concern local reactions to silicone "sweating" from the implants (gel bleed) and frank rupture, but silicone leakage has also been associated with locoregional effects such as histiocytic necrotising lymphadenitis and with systemic disorders such as autoimmune and connective tissue diseases. These side effects have led to discussion about whether silicone breast implants should be removed from the market. ${ }^{12}$ In this leader we review the specific pathological locoregional aspects of (leakage from) silicone breast implants. It is beyond the scope of this paper to discuss the pathology of silicone leakage in other parts of the body.

\section{Silicones}

Silicones are a family of polymers that comprise an alternating silicon-oxygen atom backbone. Medical silicones, or polydimethylsiloxane, can be formulated in different ways resulting in materials of varying structures and properties, such as rubbers, gels, or oils. Sometimes silicones are directly injected into the breast tissue. Mostly, silicone containing implants are used. These may be divided into four main types ${ }^{3}$ : (1) silicone rubber envelopes filled with saline; (2) silicone rubber envelopes filled with silicone gel; (3) silicone rubber envelopes covered with a polyester polyurethane foam coating; and (4) dual silicone rubber envelopes, the inner envelope containing silicone gel and the outer envelope filled with saline. Many variants exist, including differences in the outer envelope such as assorted surface textures and various chemical side groups bonded to the envelope. ${ }^{3}$ Most silicone breast implants that have been implanted up to now contain silicone gel, ${ }^{4}$ but there is a clear trend towards implants that do not contain silicones.

Silicone oils, gels, and rubbers are potentially bioactive agents that may induce host reactions, but there are many questions as to the exact biological activity of the different sili- cones and its long term significance. Commonly, a fibrous capsule forms around silicone breast implants. There is, however, in vitro ${ }^{5}$ and in vivo evidence ${ }^{6}$ that silicones may migrate into and through these capsules. On the other hand, rupture of the capsules may occur by accident, mammography, or closed capsulotomy (squeezing until the capsule ruptures, a once accepted method of disrupting a hard tissue capsule) which may facilitate migration of silicones into the surrounding breast. The frequency of asymptomatic rupture of silicone rubber envelopes has been estimated to be between $0.2 \%$ and $4 \%,{ }^{3}$ and increases with aging of the implant. ${ }^{67}$ Once outside the envelope, silicones may disperse through soft tissue, ${ }^{8}$ lymph nodes, ${ }^{9-12}$ or the vasculature ${ }^{13}$ to distant sites. ${ }^{14-17}$

Silicones are easily detected in tissue ${ }^{3618}$ as small round to irregular translucent droplets of amorphous refractile non-polarising material. ${ }^{6}{ }^{12}{ }^{18}$ Sections thicker than $4 \mu \mathrm{m}$ (for example $10-30 \mu \mathrm{m}$ thick) prevent the loss of silicone droplets during tissue processing. Adding stamp pad ink to the mounting medium permits the detection of silicones through negative staining. Non-Koehler, phase contrast, and darkfield microscopy help to highlight silicones. ${ }^{19}$ Although the picture of silicones in tissue sections is rather typical, the chemical identity can be confirmed by infrared imaging spectroscopy ${ }^{20}$ or Fourier transform infrared spectroscopy, ${ }^{21}$ electron microscopy coupled with energy dispersive $x$ ray analysis, or even more complicated techniques. ${ }^{19} 22$ There is no consensus about the usefulness of fat stains to visualise silicones. ${ }^{19}$

\section{Pathology}

FIBROUS CAPSULE

A fibrous capsule usually forms around silicone breast implants. This is a relatively hypocellular membrane of rather uniform thickness, rich in collagen. Directly next to where the implant was situated there may be a thin discontinuous layer of activated, sometimes epithelioid, myofibroblasts, ${ }^{18}$ and a thin acellular protein film between implant and capsule has also been described. ${ }^{3}$ In this membrane and directly below it there are usually foam cells and lymphocytes, often in large numbers. Figure 1 shows a typical example of a capsule surrounding a silicone breast implant. In our own series of 71 implants (table 1), only five showed no
Accepted for publication 11 March 1998 


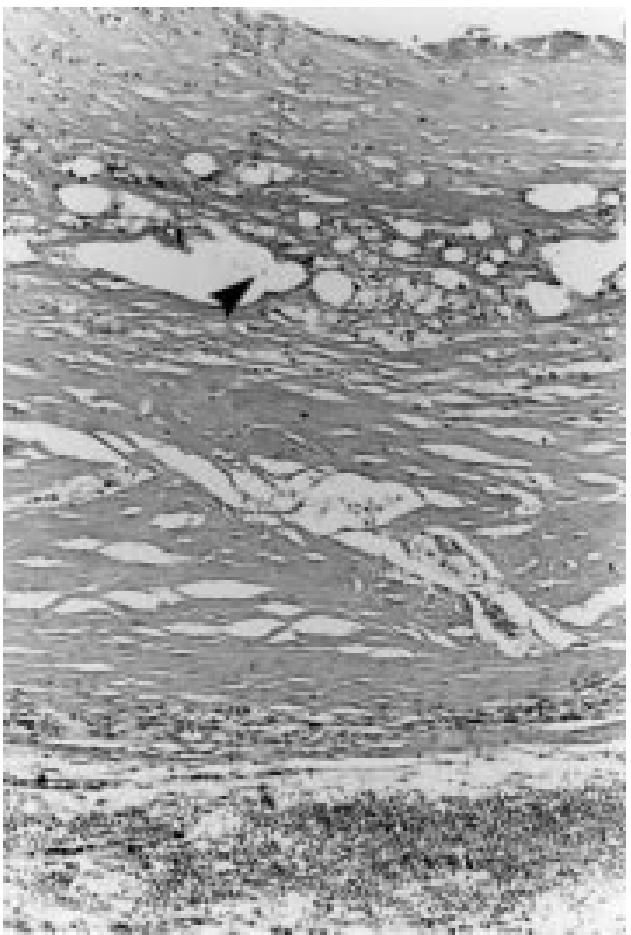

Figure 1 Typical example of a capsule surrounding a silicone breast implant. Note the typical pattern of oval to round holes, which are only partly filled with silicones, recognisable as small round to irregular translucent droplets of amorphous refractile non-polarising material (arrow). Throughout the capsule, foam cells are present. At the bottom (outside the capsule), there is a prominent lymphocytic infiltrate.

foam cells in the material examined. Thirty nine showed some foam cells, while 27 showed many. Four capsules showed no inflammation, 65 some, and two extensive lymphocytic infiltration. Plasma cells are only rarely observed in the inflammatory infiltrate. ${ }^{3}$ Calcification of the capsule is common around implants that have been in situ for many years, ${ }^{6}{ }^{23}$ and extensive calcification seems to be somewhat protective against silicone leakage. ${ }^{6}$

Silicone leakage into the capsule is characterised by a typical pattern of oval to round holes, which are only partly filled with silicones, recognisable as small round to irregular translucent droplets of amorphous refractile non-polarising material (fig 1). In our series, ${ }^{6}$ we have classified the degree of leakage through the capsule into four stages. In stage I, there are no signs of silicone leakage; in stage II, there are evident silicone particles in the capsule, confined to the inner half of the capsule; in stage III, silicone leakage into the outer half of the capsule is observed; and in stage IV, there is transmural leakage (fig 2). This staging system appeared to be correlated with the duration of implantation. ${ }^{6}$

In case of silicone leakage, giant cells of the foreign body type may be found (fig 3), although they are found in a minority of cases (35\% in our series). They are most common in cases with advanced leakage (stage III and IV).

In contrast to the regular capsules bordering smooth surfaced implants, capsules around textured implants have an irregular inner surface festooned with small knob-like projec-
Table 1 Histological changes in fibrous capsules surrounding 71 mammary silicone prostheses*

\begin{tabular}{|c|c|}
\hline Feature & Number of cases \\
\hline \multicolumn{2}{|c|}{ Stage of silicone migration } \\
\hline None & 4 \\
\hline$\leqslant 1 / 2$ & 26 \\
\hline$>1 / 2$ & 24 \\
\hline \multicolumn{2}{|l|}{ Foam cells } \\
\hline None & 5 \\
\hline Some & 39 \\
\hline Many & 27 \\
\hline \multicolumn{2}{|c|}{ Inflammation } \\
\hline None & 4 \\
\hline Some & 65 \\
\hline Much & 2 \\
\hline \multicolumn{2}{|l|}{ Giant cells } \\
\hline None & 46 \\
\hline Some & 20 \\
\hline Many & 5 \\
\hline \multicolumn{2}{|c|}{ Calcification } \\
\hline None & 56 \\
\hline Some & 12 \\
\hline \multirow{2}{*}{\multicolumn{2}{|c|}{$\begin{array}{l}\text { Much } \\
\text { Synovial metaplasia }\end{array}$}} \\
\hline & \\
\hline Absent & 64 \\
\hline Present & 7 \\
\hline
\end{tabular}

${ }^{\star}$ For a description of patient data, see reference 6 . Since these patients had had their implants removed, the data probably reflect the worst case scenario.

tions with trapped irregular solid silicone elastomer fragments. ${ }^{18}$

The capsules around saline filled implants, on the other hand, show a predominantly fibroblastic reaction, with macrophages primarily occupying the interfacial zone between the fibrous scar and the silicone rubber surface. ${ }^{3}$ The typical partly silicone filled, round to oval vacuoles are lacking, but a few fragments of solid silicone elastomer may be found. ${ }^{18}$ The capsule around implants coated with polyurethane foam seems to show a similar pattern, although giant cells may be more prevalent and lymphocytes and plasma cells are scarcer. ${ }^{324}$ Kasper ${ }^{18}$ found the inflammatory reaction in such capsules to be sarcoidal in nature with asteroid bodies containing epithelioid histiocytes. Polyurethane is non-polarising or partially polarising and shows an unusual geometric crystalline substructure. ${ }^{18}$

\section{GRANULOMAS}

Granulomas as a reaction to silicone (sometimes referred to as "siliconomas") will mainly be found after extracapsular rupture of an implant and after injections with silicones. ${ }^{13} 25$ Such silicone granulomas may present as a tumour, sometimes some distance from the implant. ${ }^{18}$ In case of injections with liquid silicones, the histological pattern seems to be numerous cystic spaces and vacuoles partly filled with silicones surrounded by a thin layer of fibrous tissue, with only minimal foreign body giant cell reaction. ${ }^{13}$ In case of extracapsular rupture, there may be many giant cells of the foreign body type, often containing silicones, and foam cells as well as lymphocytes.

SYNOVIAL METAPLASIA

After surgical implantation, breast implants move about to a varying degree. The continuous presence of this gliding foreign object induces changes in the innermost layer of fibroblastic cells surrounding the implant 


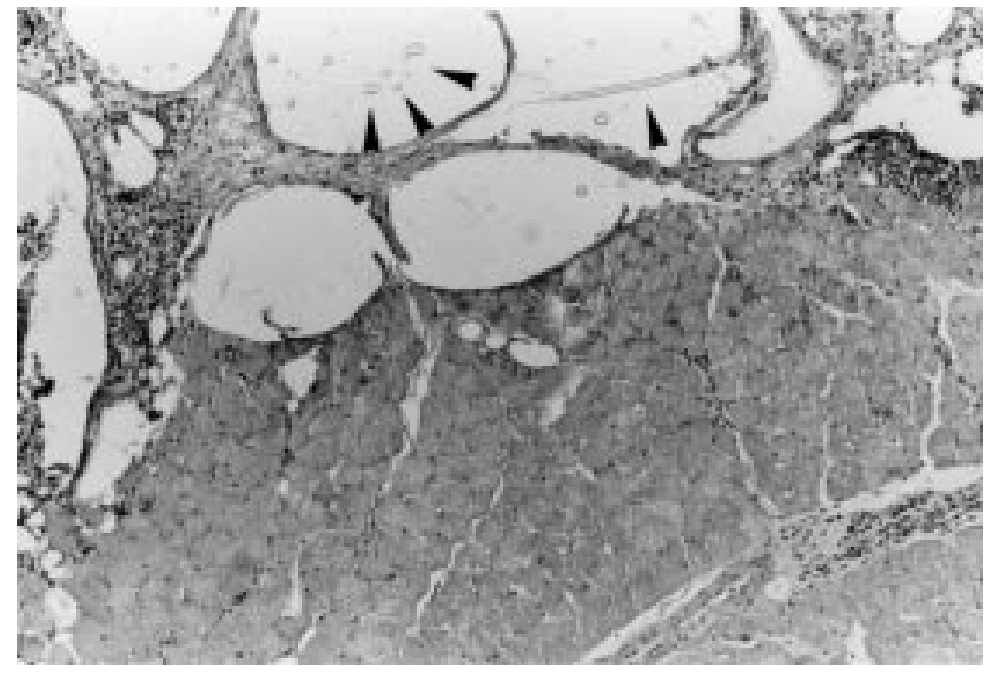

Figure 2 Extensive transmural silicone leakage (arrows) next to striated muscle.

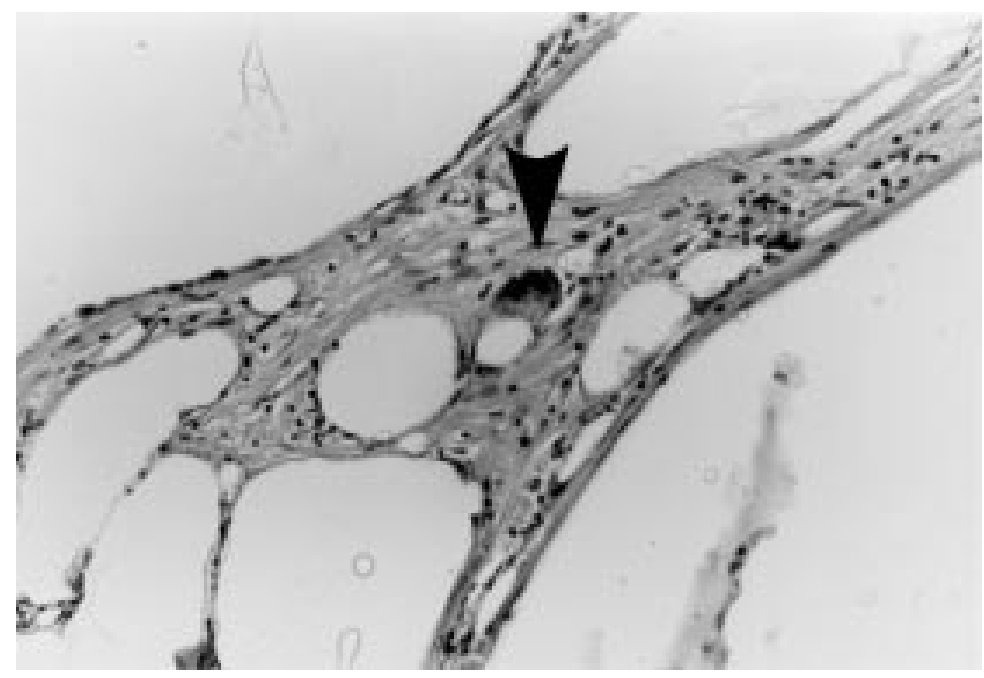

Figure 3 Silicone particles (in cystic spaces and inside a foreign body type giant cell (arrow).

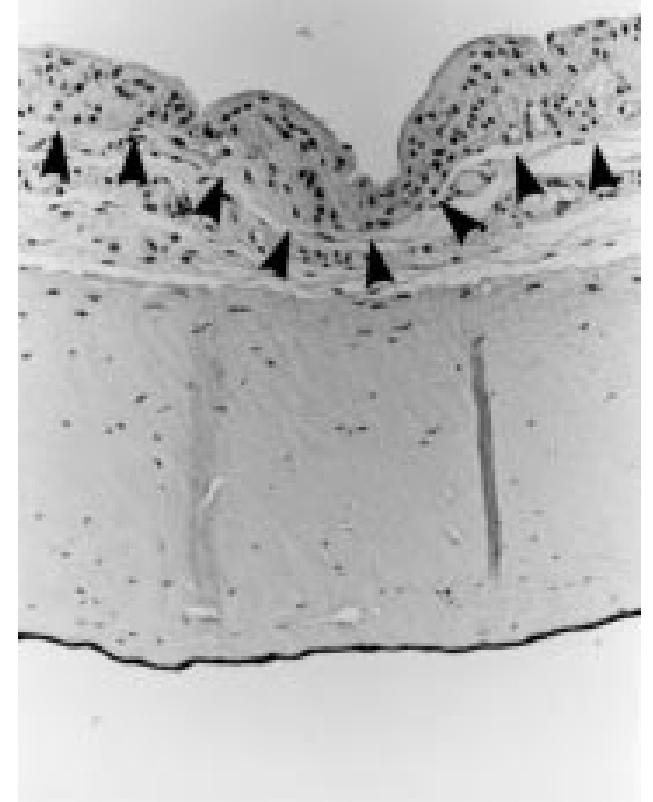

Figure 4 Synovial metaplasia on the inner side of a fibrous capsule surrounding a silicone breast implant. Note a several cells thick layer of large, mostly polygonal epithelioid cells of various sizes.

metaplasia was seen seven times $(10 \%)$. Figure 4 shows an example of synovial metaplasia.

SQUAMOUS METAPLASIA AND CARCINOMA

Kitchen et al described a case with a thin lining of squamous epithelium around a breast implant. ${ }^{29}$ A second case ${ }^{29} 30$ showed focally acanthotic and hyperkeratotic squamous epithelial lining around a breast implant, but much of the capsular wall surrounding the implant was lined by strands and nests of cells with pleomorphic and hyperchromatic nuclei, and individual cell dyskeratosis and atypical mitotic figures, which infiltrated the stroma around the capsule but not the surrounding breast tissue. Immunohistochemistry showed strong reactivity for cytokeratin. This lesion was therefore interpreted as a poorly differentiated squamous cell carcinoma. There were no lymph node metastases on mastectomy with axillary dissection.

It was hypothesised that there may occasionally be a proliferation of ductal cells around implant capsules that develop squamous metaplasia in response to chronic irritation from the indwelling breast implant. Squamous cell carcinoma has been known to arise in long standing chronic inflammation in other sites. Squamous metaplasia may only be focally present and it may thus be missed on routine investigation. Still, squamous cell carcinoma seems to be a very rare complication. The extent to which the silicones themselves play a role in the oncogenesis of such squamous cell carcinomas was felt to be unclear. ${ }^{29}$

KIKUCHI DISEASE

Sever et al described a patient with a leaky silicone breast implant with homolateral axillary cially been reported around implants with textured surface. ${ }^{28}$ In our own series of 71 capsules around smooth breast implants, synovial 
lymphadenopathy in which silicones were identified surrounded by foreign body giant cells. ${ }^{10}$ One of the lymph nodes showed histiocytic necrotising lymphadenitis (Kikuchi disease), which was interpreted as a localised aberrant immune response, related to a sudden challenge of the macrophage system posed by large amounts of silicones. Three years later, the patient was still free of any evidence of systemic immune disorders. So far, no other cases have been described, but a causal relation is not unlikely since Kikuchi disease has also been associated with systemic lupus erythematosus. Nevertheless, if Kikuchi disease occurs in relation with silicone implant leakage, this case suggests that it may be a transient reaction.

LYMPH NODES

Whenever silicones have reached the lymph nodes, they seem to be phagocytosed by multinucleated giant cells. These giant cells have uniformly distributed nuclei with abundant eosinophilic cytoplasm and prominent vacuoles, partly containing silicone gel. ${ }^{9}$ Tatabowski et al described fine needle aspiration cytology of an enlarged axillary lymph node in a patient with silicone breast implants in situ for 14 years. ${ }^{11}$ A cellular sample was obtained in which there were numerous mononucleated and giant multinucleated macrophages with striking cytoplasmic vacuolisation, containing refractile, homogeneous, and faintly yellow (Papanicolaou staining) material that was not birefringent, identified as silicone by analytical electron microscopy. Some macrophages were asymmetrically distorted by rigid silicone globules. Histological examination of the resected lymph node confirmed this picture.

\section{LYMPHOMA}

Cook et al described a patient with a breast implant for reconstruction after mastectomy for breast cancer, who developed a small palpable nodule next to the contracted and ruptured capsule. ${ }^{31}$ On microscopy, the capsule showed a foreign body giant cell reaction to silicone and polyurethane. ${ }^{32} 33$ The nodule showed a similar reaction, with an adjacent well delineated nodular proliferation of neoplastic $B$ lymphocytes, a mixture of centrocytes and centroblasts. Bcl-2 staining was positive in the neoplastic follicles, and polymerase chain reaction showed gene rearrangement of the $\mathrm{JH}$ immunoglobulin heavy chain gene, indicating a clonal proliferation of $\mathrm{B}$ cells. This led to the diagnosis of extranodal follicular mixed (centroblastic/centrocytic) B cell non-Hodgkin lymphoma, which was found also in the bone marrow. The proximity of this lymphoma to a silicone induced granulomatous reaction suggests a relation between the development of lymphoma and rupture and leakage of the silicone breast implant. However, coincidence cannot be excluded as only one case has been described so far.

\section{Systemic effects}

Earlier reports that silicone is biologically relatively inert have recently been challenged, and the question has arisen as to whether silicones can cause systemic effects after they have been freed from the implant by bleed or rupture. The following mechanism has been proposed to explain an interaction between silicones and the immune system. ${ }^{3}$ After silicones have been freed from the implant, they come in contact with native tissue, which may lead to denaturation of tissue macromolecules such as fibronectin, fibrinogen, and apolipoprotein B. The denatured macromolecules are sufficiently different from native tissue to be recognised as foreign, which may trigger activation of the immune system and lead to generation of antibodies against them. These antibodies may cross react with native tissue, generating an autoimmune response.

Anecdotal case reports and case series have reported autoimmune and connective tissue diseases in patients with breast implants, but large epidemiological studies have failed to support an association between silicone breast implants and the known autoimmune and connective tissue diseases (for reviews, see Noone ${ }^{34}$ and Silverman $e t a l^{4}$ ).

\section{Risk of breast cancer}

Breast implants impair the effectiveness of mammography in detecting neoplasms, ${ }^{35}$ but there does not seem to be an increased risk of breast cancer in patients with silicone breast implants (for reviews see Noone ${ }^{34}$ and Silverman et $a l^{4}$ ).

\section{Conclusion}

Leakage from silicone breast implants may lead to a variety of locoregional pathological processes with a more or less specific morphology. In general, the incidence of these pathological processes will increase with implant age. As yet, there is insufficient evidence for systemic effects of silicone leakage such as autoimmune and connective tissue diseases, and there does not seem to be an increased risk of breast cancer in patients with silicone breast implants.

1 Angell M. Breast implants-protection or paternalism? $N$ Engl f Med 1992;326:1695-6.

2 Kessler DA. The basis for the FDA's decision on breast implants. N Engl f Med 1992;326:1713-35.

3 Kossovsky N, Freiman CJ. Silicone breast implant pathology. Clinical data and immunologic consequences. Arch Pathol Lab Med 1994;118:686-93.

4 Silverman BG, Brown SL, Bright RA, et al. Reported complications of silicone gel breast implants: an epidemiologic review. Ann Intern Med 1996;124:744-56.

5 Bergman RB, van der Ende AE. Exudation of silicone through the envelope of gel-filled breast prostheses: an in through the envelope of gel-filled breast
vitro study. Br f Plast Surg 1979;32:31-4.

6 Beekman WH, Feitz R, van Diest PJ, et al. Migration of silicone through the fibrous capsule around silicone mammary prosthesis following intracapsular failure. Ann Plast mary prosthesis followi

7 Camarg DL de, Sheridan JM, Kammer BA. Rupture and Camara DL de, Sheridan JM, Kammer BA. Rupture and
aging of silicone breast implants. Plast Reconstr Surg 1993; 91:828-34.

8 Thomsen JL, Christensen L, Nielsen M, et al. Histologic changes and silicone concentrations in human breast tissue surrounding silicone breast prostheses. Plast Reconstr Surg 1990;85:38-41.

9 Hausner RJ, Schoen FJ, Pierson KK. Foreign-body reaction to silicone gel in axillary lymph nodes after an augmentation mammaplasty. Plast Reconstr Surg 1978;62:381-4.

10 Sever CE, Leith CP, Appenzeller J, et al. Kikuchi's histiocytic necrotizing lymphadenitis associated with ruptured silicone breast implant. Arch Pathol Lab Med 1996;120:380-5.

11 Tabatowski K, Elson DCE, Johnson W. Silicone lymphadenopathy in a patient with a mammary prosthesis: fine needle aspiration cytology, histology, and analytical electron microscopy. Acta Cytol 1990;34:10-14. 
12 Truong LD, Cartwright J, Goodman MD, et al. Silicone lymphadenopathy associated with augmentation mammaplasty. Morphologic features of nine cases. Am 7 Surg Pathol 1988;12:484-91.

13 Travis WD, Balogh K, Abraham JL. Silicone granulomas: report of three cases and review of the literature. Hum Pathol 1985;16:19-27.

14 Capozzi A, Du Bou R, Pennisi VR. Distant migration of silicone gel from a ruptured breast implant. Plast Reconstr Surg 1978;62:302-3

15 Celli B, Textor S, Kovnat DM. Adult respiratory distress syndrome following

16 Huang TT, Blackwell SJ, Lewis SR. Migration of silicone gel after the squeeze technique to rupture a contracted breast capsule. Plast Reconstr Surg 1978;61:277-80.

17 Silver RM, Sahn EE, Allen JA, et al. Demonstration of silicon in sites of connective-tissue disease in patients with

18 Kasper SC. Histologic features of breast capsules reflect surface configuration and bad composition of silicone bag implants. Am f Clin Pathol 1994;102:655-9.

19 Raso DS, Greene WB, Veseley JJ, et al. Light microscopic techniques for the demonstration of silicone gel. Arch Pathol Lab Med 1994;118:984-7.

20 Kidder LH, Kalasinsky VF, Luke JL, et al. Visualization of silicone gel in human breast tissue using new infrared imaging spectroscopy. Nature Med 1997;3:235-7.

21 Hardt NS, Yu LT, La Torre G, et al. Fourier transform microspectroscopy used to identify foreign materials related to breast implants. Mod Pathol 1994;7:669-76.

22 Roggli VL, McDonald JW, Shelburne JD. The detection of silicone within tissues. Arch Pathol Lab Med 1994;118:9634.

23 Emery JA, Spanier SS, Kasnic G, et al. The synovial structure of breast-implant-associated bursae. Modern Pathol 1994;7:728-33.
24 Cocke WM, Leathers HK, Lynch JB. Foreign body reactions to polyurethane covers of some breast prostheses. Plast Reconstr Surg 1975;56:527-30.

25 Padadopoulos T. The silicone-injected breast and its dilemmas. Breast 1997;6:51-3.

26 Raso DS, Greene WB, Metcalf JS. Synovial metaplasia of a periprosthetic breast capsule. Arch Pathol Lab Med 1994;118:249-51.

27 Raso DS, Crymes LW, Metcalf JS. Histological assessment of fifty breast capsules from smooth and textured augmentation and reconstruction mammoplasty prostheses with emphasis on the role of synovial metaplasia. Mod Pathol 1994;7:310-16.

28 Bleiweiss IJ, Copeland M. Capsular synovial metaplasia and breast implants [letter]. Arch Pathol Lab Med 1995;119: 115.

29 Kitchen SB, Paletta CE, Shehadi SI, et al. Epithelialization of the lining of a breast implant capsule. Possible origin of squamous cell carcinoma associated with a breast implant capsule. Cancer 1994;73:1449-52.

30 Paletta C, Paletta FX. Squamous cell carcinoma following breast augmentation. Ann Plast Surg 1992;29:425-32.

31 Cook PD, Osborne BM, Connor RL, et al. Follicular lymphoma adjacent to foreign body granulomatous inflammation and fibrosis surrounding silicone breast prosthesis. Am $\mathcal{F}$ Surg Pathol 1995;19:712-17.

32 Bleiweiss IJ, Copeland M. Breast prosthesis reaction [letter]. Am f Surg Pathol 1996;20:505-6.

33 Fitzgibbons PL. Breast prosthesis reaction [letter]. Am $\mathcal{f}$ Surg Pathol 1996;20:505.

34 Noone RB. A review of the possible health implications of silicone breast implants. Cancer 1997;79:1747-56.

35 Carlson GW, Curley SA, Martin JE, et al. The detection of breast cancer after augmentation mammaplasty. Plast Reconstr Surg 1993;91:837-40. 